\title{
Integration of Economic Load Dispatch with Wind Penetration
}

\author{
Bibekananda Jena, Sonali Goel, Renu Sharma
}

\begin{abstract}
Wind energy is a form of inexhaustible energy that can be utilized deprived the use of fuel to produce energy and can save the fuel expenses of the electricity system. With rising oil rates and environmental contamination, it has now become clear that wind energy should be deemed a useful solution to the production of thermal energy. In order to continue with the quest for solutions to conventional energy technologies, it is essential to include wind penetration in the Economic load dispatch issue. This paper discloses a model to involve wind penetration in the Economic load dispatch issue and, in relation to the standard economic dispatch variables, includes the convergence to reduce the number of iterations.
\end{abstract}

Keywords: economic load dispatch, wind penetration, electricity system.

\section{INTRODUCTION}

The most significant issue in the preparation and implementation of the electrical power generation scheme is the efficient configuration of all generators in the scheme to fulfill the necessary requirement. Economic Load Dispatch (ELD) is a situation in which an ideal mix of power price of electricity while meeting load demand and many operating limitations. Optimization of economic dispatch is of the ultimate financial significance to a service provider in an unregulated electricity market. The effective and optimal economic functioning of electrical power structures has always been a significant part of the electrical power industry. The primary goal of the ELD issue is to significantly reduce operating costs by fulfilling the multiple operating limitations in an attempt to meet the load demand. Several conventional techniques are used to optimize ELD problems, but in these strategies, the actual cost curves of the components are thought to be monotonically growing linear functions in a piecewise manner, but the useful systems are non-linear. The Economic Load Dispatch (ELD) can be described as the method of assigning generation amount to the building systems so that the system load is provided fully and most economically. For an interlinked scheme, it is essential to reduce costs. The economic load dispatch shall be used to identify the level of production of every plant, such that the overall cost of generation and transmission shall be as low as the recommended load schedule. The goal of dispatching financial loads is to

Revised Manuscript Received on September 14, 2019.

Bibekananda Jena, Department of Electrical Engineering, Institute of Technical Education and Research, Siksha 'O' Anusandhan(Deemed to be University), Bhubaneswar, Odisha, India.

Sonali Goel, Department of Electrical Engineering, Institute of Technical Education and Research, Siksha 'O' Anusandhan(Deemed to be University), Bhubaneswar, Odisha, India.

Renu Sharma, Department of Electrical Engineering, Institute of Technical Education and Research, Siksha 'O' Anusandhan(Deemed to be University), Bhubaneswar, Odisha, India.(Email: renusharma@soa.ac.in) generation systems is chosen in order to reduce the complete

mitigate the general expense of production. The technique of financial charge delivery for producing systems at distinct locations must have the complete price of electricity at the lowest possible point. The economic load dispatch (ELD) problem presumes that the proportion of power to be provided by a particular set of continuous units for a particular time period and aims to reduce the cost of providing this energy subject to the constraints of the producing units. It is therefore linked to the minimizing of full costs over the full shipment cycle. The primary objective of the financial charge transfer issue is therefore to mitigate the complete expense of producing actual energy (manufacturing) at different locations while at the same time fulfilling the demands and costs of the transmission connections. In the latest decades, it has become very essential for services to operate their energy stations at a minimum price while at the same moment fulfilling their customers ' requirements and attempting to create a profit. With a limited stock of generators and a big boost in energy demand, energy price and storage restriction, the assigned devices should optimally meet the anticipated load requirement with modifications in transport costs and uncertainties in the load demand prediction at the diverse interval of time. In the case of economic load dispatch, generations are not corrected, but they are permitted to hold values again within certain boundaries in order to satisfy the specific load demand with the lowest energy utilization. Wind power is intensifying at a pace of 30 percent annually with a global installed capacity of 238,000 megawatts at the beginning of 2011. The modification of the power consumption framework and the creation of renewable energy are encouraged owing to severe global energy and environmental issues. Wind power as a significant type of renewable energy apps is undergoing fast growth. It is a multi-variable and multi-restricted, extremely non-linear, issue of the economic distribution of the energy scheme, comprising wind turbines. The average operating capacity of the wind generator in India has risen from $250 \mathrm{~kW}$ in the 1990s to $1 \mathrm{MW}$ total per operational wind turbine currently. This issue region has gone on a delicate aspect, as the audience has become progressively worried with environmental concerns so that economic dispatch now involves the delivery of technologies to reduce pollutants and preserve multiple types of energy, as well as the achievement of lowest possible costs. In fact, there is a need to extend the restricted financial optimization issue to integrate scheme operating limitations to guarantee structure safety, thereby stopping the structure from collapsing owing to unforeseen circumstances.

Published By:

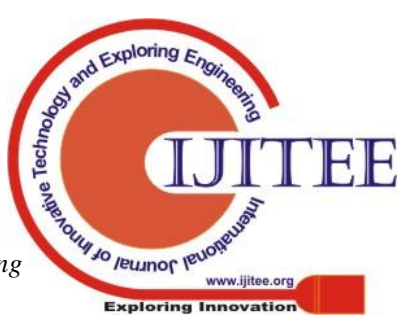




\section{RELATED WORK}

Economic dispatch (ED) works with the lowest possible price of power generation in the assessment of electrical power systems[1]-[6]. Several studies have stared at the forecast of wind speed for usage in the determination of accessible wind power. These studies were focused on principles such as fuzzy logic[7]-[10], neural networks[11], [12] and time series. the economic dispatch model to include wind-powered generators is created, using ideas based on fuzzy set theory. as a constrained optimization problem, economic load dispatch can be addressed by the lambdaiteration method [13], the gradient method [14] and the projection method. However, these traditional computational methods require that the cost features be constantly differentiable and convex, and therefore cannot be implemented to the economic load dispatch since the existence of transfer speed boundaries, forbidden operating areas and valve-point impacts make the cost functions concerned invariably discontinuous and/or non-convex, classical models, the authors of [15]attach a penalty price criterion for not using the accessible wind power ability. A fuzzy wind boundary is described where wind measurements below a certain minimum are deemed to be fully appropriate on the basis of safety issues and wind measurements above a certain peak are deemed to be inappropriate for system safety purposes. Intelligent met heuristic models have been introduced to economic load dispatch over the previous two centuries, without needing a constant or small price feature [16]. Specifically, genetic algorithm and enhanced genetic algorithm were utilized in[17]-[19]to fix the economic load dispatch with valvepoint impacts. In [20]-[22], PSO and mixed PSO models have been used for nonlinear economic load dispatch resolution due to banned operating areas, boost speed constraints and valve-point impacts."Artificial Bee colony optimization model" for multi-area financial shipment was provided in. the altered "harmony search algorithm" for economic load dispatch was suggested in [23], taking into account environmental effects. a hybrid harmony search matrix for the solution of , as well as a multi-area economic load dispatch, was created in [16]. moreover, all of the above functions are associated only with heat generators and do not utilize renewable energies.

\section{PROPOSED WORK}

The ED issue is intended to evaluate the optimum charging of all the devices involved in order to lessen the cost function topic to scheme limitations

The equation for minimizing is given below:

(1)

$$
\mathrm{y}=\sum_{\mathrm{i}=1}^{\mathrm{n}}\left(\mathrm{q}_{\mathrm{io}}+\mathrm{q}_{\mathrm{i} 1} \mathrm{x}_{\mathrm{i}}+\mathrm{q}_{\mathrm{i} 2} \mathrm{x}_{\mathrm{i}}^{2}\right)
$$

Subjected to

$$
\begin{gathered}
\mathrm{x}_{\min , \mathrm{i}} \leq \mathrm{x}_{\mathrm{i}} \leq \mathrm{x}_{\max , \mathrm{i}}, \quad(\mathrm{i}=1,2 \ldots, \mathrm{n}) \\
\sum_{\mathrm{i}=1}^{\mathrm{n}} \mathrm{x}_{\mathrm{i}}=\mathrm{P}_{\mathrm{d}}+\mathrm{P}_{\mathrm{s}}
\end{gathered}
$$

In this implementation, let the unit of "xi" is megawatts (MW), then the units of q_i0,q_i1,q_i2 are corresponding "\$/h, $\$ / M W h$, and $\$$ / \MW】^2 h". As a result, the unit of
" $y$ " is " $\$ / h "$. In numerical assessment, the scheme is generally used per unit (p.u.) where the foundation is " 100 MVA". This current work discloses an enhanced economic load dispatch system to eliminate energy costs and to adopt the stochastic wind penetration as a constraint.

Wind speed "V (m / s)" is a random variable. The CDF for the allocation of "Weibull" is:

$$
F_{V}(v)=1-\exp \left[-(v / c)^{k}\right]
$$

Where "c $>0$ " and" $\mathrm{k}>0$ " are simultaneously referred to as the variable of scale and the variable of form. Please note that there are two special cases. The instances of " $\mathrm{k}=1$ and $\mathrm{k}=2$ " add to the exponential distribution and the "Rayleigh distribution", respectively. In the literature, the majority of research embraced has taken " $\mathrm{k}=2$ ". The pdf of "V" corresponds to its CDFis :

$$
f_{V}(v)=\frac{k}{c}(v / c)^{k-1} \exp \left[-(v / c)^{k}\right]
$$

The association among the initial wind power and the total electrical power depends on a number of variables, including the efficiency of the "generator, the wind rotor, the gearbox" and the inverter, based on the type of power generation system being researched. The streamlined framework is employed for the standard wind penetration device is to categorize the relationship between Wind power and wind speed.

$$
W=\left\{\begin{array}{l}
0,\left(V<v_{\text {in }} \text { or } V \geq v_{\text {out }}\right) \\
w_{r}, \quad\left(v_{r} \leq V<v_{\text {out }}\right) \\
\frac{\left(V-v_{\text {in }}\right) w_{r}}{v_{r}-v_{\text {in }}},\left(v_{\text {in }} \leq V<v_{r}\right)
\end{array}\right.
$$

(6)

\section{POWER BALANCE:}

The entire generating power has to be equivalent to the sum of load demand and transmission line loss.

$$
\sum_{\mathrm{i}=1}^{\mathrm{n}} \mathrm{x}_{\mathrm{i}}=\mathrm{P}_{\mathrm{d}}+\mathrm{P}_{\mathrm{s}}
$$

wind penetration the power balance constraint becomes

$$
\sum_{\mathrm{j}=1}^{\mathrm{n}} \mathrm{x}_{\mathrm{j}}+\Omega(\mathrm{W})=\mathrm{P}_{\mathrm{d}}+\mathrm{P}_{\mathrm{s}}
$$

The association between input power and wind speed is highly nonlinear. One of the representative models is

$$
P_{w}=0.5 \rho A_{s} V^{3}
$$


Where $P_{w}$ is the input wind power (watts), $\rho$ is the air density $\left(\mathrm{kg} / \mathrm{m}^{3}\right), A_{s}$ is the cross-sectional area by which the wind passes $\left(\mathrm{m}^{2}\right), \mathrm{v}$ is wind speed and $\mathrm{V}$ is the wind $\operatorname{speed}(\mathrm{m} / \mathrm{sec})$ is a random variable $(\mathrm{RV})$.

According to "Weibull distribution cumulative distribution function (CDF)" is:

$$
F_{V}(v)=1-\exp \left[-(v / c)^{k}\right]
$$

Where $\mathrm{c}>0$ and $\mathrm{k}>0$ are mentioned as the scale factor and shape factor, respectively.

The "probability density function" (PDF) of $\mathrm{V}$ is:

$$
f_{V}(v)=\frac{k}{c}(v / c)^{k-1} \exp \left[-(v / c)^{k}\right]
$$

The relation between wind power and wind speed:

$$
W=\left\{\begin{array}{c}
0,\left(V<v_{\text {in }} \text { or } V \geq v_{\text {out }}\right) \\
w_{r}, \quad\left(v_{r} \leq V<v_{\text {out }}\right) \\
\frac{\left(V-v_{i n}\right) w_{r}}{v_{r}-v_{\text {in }}},\left(v_{\text {in }} \leq V<v_{r}\right)
\end{array}\right.
$$

The power balance constraint becomes

$$
\sum_{i=1}^{n} x_{i}=P_{d}-w_{r} h_{p}
$$

One of the primary issues is to characterize wind power in the economic load dispatch model. The traditional way of solving this issue is to utilize average wind penetration. This way can be easily executed, called "probabilistic infeasibility":

Minimize $\mathrm{z}=2 t_{1}+t_{2}$

Subject to $A t_{1}+t_{2} \geq 10$;

$$
\begin{gathered}
B t_{1}+t_{2} \geq 8 \\
t_{1} \geq 0 ; \quad t_{2} \geq 0
\end{gathered}
$$

\section{ELD MODEL WITH EQUALITY CONSTRAINT}

This paper produces and fixes two ELD designs that are restricted by the deterministic metric[1 ]. The first model, ELD EQ, has a closed-ended alternative. The second model, ELD INEQ, involves more limitations and has no closedform solution.

$$
\operatorname{Pr}\left(W+\sum_{i=1}^{n} x_{i} \leq P_{d}\right)=P_{a}
$$

In which $\mathrm{W}$ reflects all of the Wind Power to be delivered, and $\mathrm{P}$ a is a designated threshold that reflects the tolerance that the maximum demand for $\mathrm{P} \mathrm{d}$ can not be met. Greater $\mathrm{P}$ a means more tolerance towards inadequate production and vice versa. In order to prevent deteriorated outcomes, $\mathrm{P}$ a is selected in such a way that $\mathrm{P} \mathrm{a}(\mathrm{W}=0) \leq \mathrm{P}$ a $<1$ is selected. Since the complete WP here is defined by a single RV, it means that all wind turbines are situated in a consistent geographical region, depicted by a tiny wind farm or a group of turbines in a big wind farm. The transmission loss is excluded because the transmission range is usually short and, in such conditions, $\mathrm{P} \mathrm{s}$ is relatively small compared to the actual power.

$$
\begin{aligned}
& \sum_{i=1}^{n} x_{i}=P_{d}-w_{r} h_{p} \\
& h_{p}=\frac{c}{v_{r}-v_{i n}}\left|\ln \left[1+\exp \left(-\frac{v_{\text {out }}^{k}}{c^{k}}\right)-P_{a}\right]\right|^{\frac{1}{k}}-\frac{v_{i n}}{v_{r}-v_{i n}} \\
& \sum_{i=1}^{n} x_{i}=P_{d}
\end{aligned}
$$

This means that the maximum load should be provided by the energy produced by heat generators.

\section{RESULTS AND DISCUSSIONS}

In this paper for the simulation purpose, the total load demand is taken "9.0 MW", wind power of respective wind turbine is "1.0 MW", scale factor is taken 15 , wind speed is taken as " $15 \mathrm{~m} / \mathrm{s}$ ", cut-in wind speed is taken as " $5 \mathrm{~m} / \mathrm{s}$ ", and cut off wind speed is taken as " $45 \mathrm{~m} / \mathrm{s}$ ". The average loss during transmission is ignored in this simulation. And the aforementioned simulation is performed on the "MATLAB" platform. Figure 1, 2 and 3 shows the graphical representation of the simulation results. Table 1 depicts the system parameters.

Table 1 system parameters

$\begin{array}{cccccc}\text { Generator index } & \text { gio } & \text { qil } & \text { qi2 } & \text { Xmin.i } & \text { Xmax.i } \\ 1 & 10 & 200 & 100 & 0.03 & 1.50 \\ 2 & 10 & 150 & 120 & 0.03 & 1.50 \\ 3 & 20 & 180 & 40 & 0.03 & 1.50 \\ 4 & 10 & 100 & 60 & 0.03 & 1.50 \\ 5 & 20 & 180 & 40 & 0.03 & 1.50 \\ 6 & 10 & 150 & 100 & 0.03 & 1.50\end{array}$

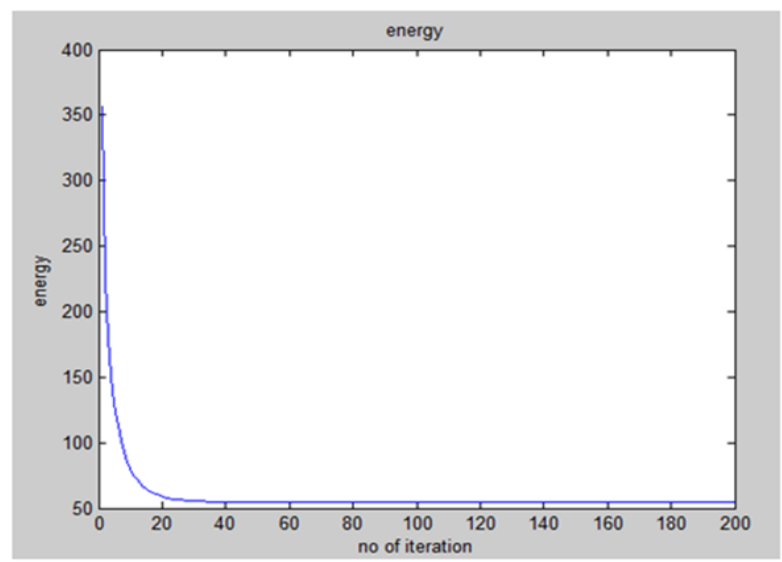

Figure 1 No. of iteration vs. energy consume 


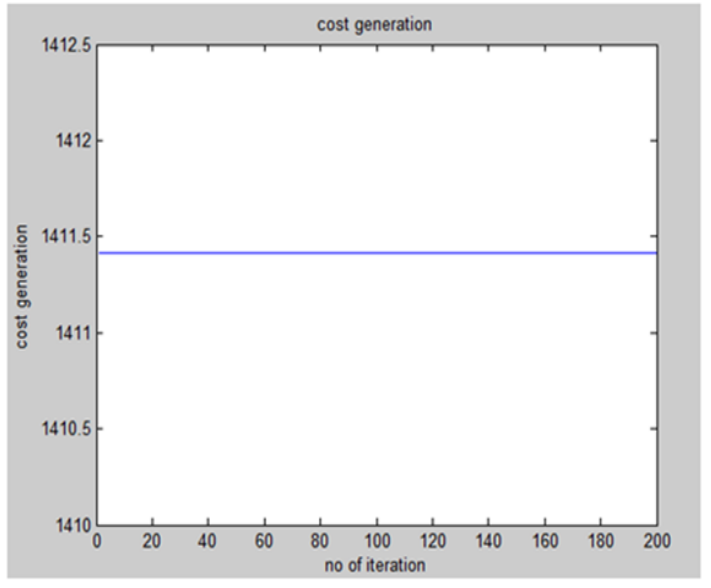

Figure 3 No. of iteration vs. cost value

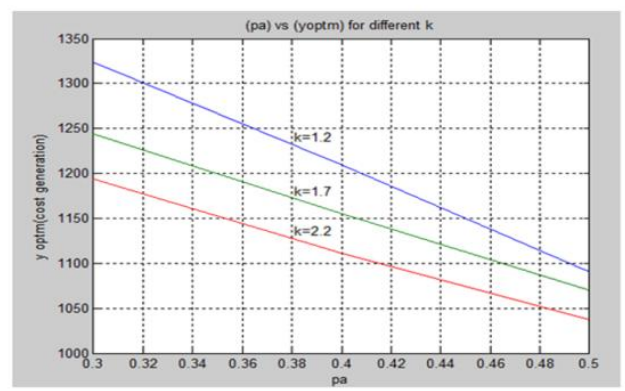

Figure 4 Optimum Solution for different shape factor (K)

\section{CONCLUSION}

Wind energy is known as inexhaustible energy, that can be utilized in the production of electricity. During this production there s no consumption of fuel, ultimately save the costing related to fuel needed in the power system. In this paper, the integration of the economic load dispatch model with wind power penetration is presented. The indeterminate nature of the wind speed as represented by Weibull. In relation to the standard economic dispatch variables, variables that compensate for both overestimation and underestimation of accessible wind power are also included. The proposed system has adopted the generic wind power generation model which is utilized to categorize the association among the wind penetration and the wind speed. Through the simulation results it is concluded that as the parameter of threshold increases and factors affecting the speed of the wind, the optimum cost value decreases. Hence the results depict that enhancement has been done to solve the aforementioned economic load dispatch problem. Furthermore, it has been depicted that the suggested integration enhances the convergence in addition to less amount of iterations.

\section{REFERENCES}

1. P. S. Kundur, "Power system stability," in Power System Stability and Control, Third Edition, 2017.

2. A. Hanson and L. Grigsby, "Power system analysis," in Systems, Controls, Embedded Systems, Energy, and Machines, 2017.

3. L. L. Grigsby, Power system stability and control. 2017.
4. P. S. Kundur, "Power system dynamics and stability," in Power System Stability and Control, Third Edition, 2017.

5. F. Gonzalez-Longatt and J. Rueda, PowerFactory Applications for Power System Analysis. 2014.

6. T. Gonen, "Power Flow Analysis," in Modern Power System Analysis, Second Edition, 2013.

7. A. E. Saleh, M. S. Moustafa, K. M. Abo-Al-Ez, and A. A. Abdullah, "A hybrid neuro-fuzzy power prediction system for wind energy generation," Int. J. Electr. Power Energy Syst., 2016.

8. Y. Noorollahi, M. A. Jokar, and A. Kalhor, "Using artificial neural networks for temporal and spatial wind speed forecasting in Iran," Energy Convers. Manag., 2016.

9. A. U. Haque, P. Mandal, M. E. Kaye, J. Meng, L. Chang, and T. Senjyu, "A new strategy for predicting short-term wind speed using soft computing models," Renewable and Sustainable Energy Reviews. 2012.

10. A. Lahouar and J. Ben Hadj Slama, "Hour-ahead wind power forecast based on random forests," Renew. Energy, 2017.

11. A. Marvuglia and A. Messineo, "Monitoring of wind farms' power curves using machine learning techniques," Appl. Energy, 2012.

12. Z. Men, E. Yee, F. S. Lien, D. Wen, and Y. Chen, "Short-term wind speed and power forecasting using an ensemble of mixture density neural networks," Renew. Energy, 2016.

13. Power Electronics, 2nd Edition. 2017.

14. S. S. Shrawane, M. Diagavane, and N. Bawane, "Concoction of UPFC for optimal reactive power dispatch using hybrid GAPSO approach for power loss minimisation," in Proceedings of 6th IEEE Power India International Conference, PIICON 2014, 2014.

15. S. Khaleghi, E. Faghihnia, A. E. Mousavi, and E. Ghahremani, "Solution to the economic dispatch problemwithout valve-point loading effect by using RLPSO algorithm," in 2014 International Congress on Technology, Communication and Knowledge, ICTCK 2014, 2015.

16. T. Sen and H. D. Mathur, "A new approach to solve Economic Dispatch problem using a Hybrid ACO-ABCHS optimization algorithm,” Int. J. Electr. Power Energy Syst., 2016.

17. P. Arumugam and R. Coimbatore Subramanian, "Power search algorithm (PSA) for combined economic-emission dispatch problems considering valve point effects in economic load dispatch," Turkish J. Electr. Eng. Comput. Sci., vol. 25, no. 6, pp. 4647-4656, 2017.

18. H. Shahinzadeh, S. M. Nasr-Azadani, and N. Jannesari, "Applications of particle swarm optimization algorithm to solving the economic load dispatch of units in power systems with valve-point effects," Int. J. Electr. Comput. Eng., vol. 4, no. 6, pp. 858-867, 2014.

19. S. Bhattacharya, B. R. Kuanr, A. Routray, and A. Dash, "Implementation of bat algorithm in economic dispatch for units with multiple fuels and valve-point effect," in Proceedings - 2017 IEEE International Conference on Electrical, Instrumentation and Communication Engineering, ICEICE 2017, 2017, vol. 2017-December, pp. 1-7.

20. J. Sun, V. Palade, X. J. Wu, W. Fang, and Z. Wang, "Solving the power economic dispatch problem with generator constraints by random drift particle swarm optimization," IEEE Trans. Ind. Informatics, vol. 10, no. 1, pp. 222-232, 2014. 
21. A. M. Ilyas and M. N. Rahman, "Economic dispatch thermal generator using modified improved particle swarm optimization," Telkomnika, vol. 10, no. 3, pp. 459-470, 2012.

22. D. L. V. N. RAO, "PSO Technique for Solving the Economic Dispatch Problem Considering the Generator Constraints," Int. J. Adv. Res. Electr. Electron. Instrum. Eng., vol. 3, no. 7, pp. 10439-10454, 2014.

23. B. Jeddi and V. Vahidinasab, "A modified harmony search method for environmental/economic load dispatch of real-world power systems," Energy Convers. Manag., 2014. 